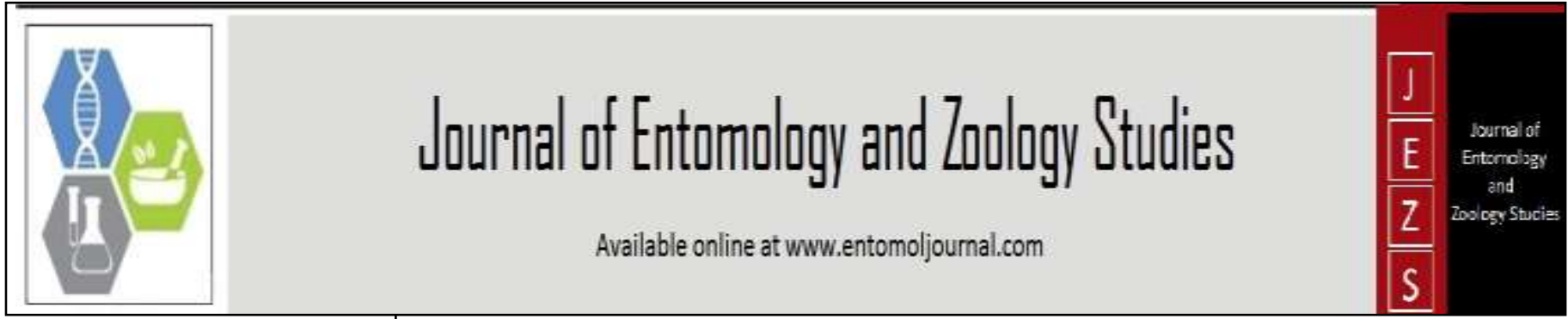

E-ISSN: 2320-7078

P-ISSN: 2349-6800

www.entomoljournal.com

JEZS 2021; 9(1): 134-139

(C) $2021 \mathrm{JEZS}$

Received: 21-11-2020

Accepted: 25-12-2020

\section{Bikash Mohapatra}

Department of Entomology,

NMCA, NAU, Navsari, Gujarat,

India

\section{Dr. CU Shinde}

Department of Entomology, NMCA, NAU, Navsari, Gujarat, India
Corresponding Author:

\section{Dr. CU Shinde}

Department of Entomology,

NMCA, NAU, Navsari, Gujarat,

India

\title{
Contact toxicity of different insecticides against egg parasitoid, Trichogramma japonicum Ashmead under laboratory condition
}

\section{Bikash Mohapatra and Dr. CU Shinde}

DOI: https://doi.org/10.22271/j.ento.2021.v9.i1b.8138

Abstract

The present investigation was undertaken to evaluate the contact toxicity of seven different insecticides against female adult of Trichogramma japonicum. The results indicated that none of the insecticide was found safer except control treatment to the female of T. japonicum under contact toxicity trial during the present investigation. However, insecticides viz., Flubendiamide 39.35 SC, chlorantraniliprole 18.5 SC and lambda-cyhalothrin 5 EC were considered as slightly harmful. Furthermore, thiamethoxam 25 WG and thiacloprid $21.7 \mathrm{SC}$ were found moderately harmful to the female of $T$. japonicum. Moreover, fipronil $5 \mathrm{SC}$ and quinalphos $25 \mathrm{EC}$ were found detrimental and grouped as harmful to the female of $T$. japonicum by causing cent per cent adult mortality.

Keywords: Trichogramma japonicum, insecticides, contact toxicity

\section{Introduction}

Biological control agents are the most significant strategies in integrated pest management programme. Among the several biological control agents successfully adopted in the pest management strategies, Trichogrammatid wasps are one of the most dominant groups of biocontrol agents with prominent attention for the management of lepidopteran pests throughout the world. Among the different genus of family Trichogrammatids, Trichogramma is the bestknown genus in the family due to its use in the biological control programme. Trichogramma $s p$. (Hymenoptera; Trichogrammatidae) are tiny wasps that occur naturally in most terrestrial ecosystems. Worldwide, a total area of more than 32 million ha of agricultural and forest lands has been annually released Trichogramma spp. to control insect pests in 19 countries ${ }^{\text {[24]. In }}$ India, about 28 Trichogrammatids are recorded against major insect pest ${ }^{\text {[25]; among }}$ them, Trichogramma chilonis Ishii, Trichogramma japonicum Ashmead, and Trichogramma acheae Nagaraja and Nagarkatti are important species. Furthermore, T. japonicum is an important hymenopteran egg parasitoid used for the management of different pests viz., rice stem borer, sugarcane borers' complex, etc. Despite the crucial role of the biological control agents in agriculture, synthetic chemical insecticides are still indispensable and these broadspectrum insecticides significantly reduce the potential of the biocontrol agents in general and in particular to parasitic Hymenoptera that are often highly susceptible to insecticides than their hosts. Insecticides may affect the effectiveness of bio-control agents either by causing direct mortality or by altering their behaviour, reproductive potential, and movement ${ }^{[5,23]}$. However, the adverse effect on biocontrol agents usually depends on the intrinsic relative toxicity of insecticides, formulation, and concentration of chemicals applied, timing, and special pattern used for application as well as environmental factors. Better results can be ascertained in the IPM programme by a judicious combination of the natural enemies and selective insecticides that will give effective management of the pest without causing much harm to natural enemies ${ }^{[10,13]}$. Moreover, the efficacy of Trichogramma is diminishing due to the extensive use of insecticides, as they are sensitive to most of the pesticides ${ }^{[12]}$. Therefore, an attempt was made by considering the importance of Trichogramma spp. in general and T. japonicum in particular for their safety against different common and new generation insecticides during the present investigation.

\section{Materials and Methods}

The present investigation was undertaken at Bio-control Laboratory, Department of Entomology, N.M.C.A., Navsari Agricultural University, Navsari. 
Insecticidal solutions of pre-decided concentrations (Table-1) were prepared in a glass beaker of 1 litre capacity and evaluated for their relative toxicity to the egg parasitoid, $T$. japonicum through contact toxicity.

\section{Mass culture of Corcyra cephalonica and egg parasitoids, T. japonicum}

The rice moth, $C$. cephalonica and $T$. japonicum were reared in Bio-control Laboratory, Department of Entomology, N.M.C.A., NAU, Navsari. Sterilized sorghum grains were used as feed for the factitious host, $C$. cephalonica and eggs of Corcyra were used for the culture of T. japonicum. The mass production of $C$. cephalonica under laboratory conditions was made as per the methodology suggested by Naganna and Shinde (2017) ${ }^{[16]}$. The eggs of Corcyra laid were collected and cleaned to remove the impurities viz., scales and other body parts of the moths by rolling them on blotting paper. Cleaned eggs of $C$. cephalonica were exposed to Ultra Violet (U.V) radiation in a U.V chamber for 45 minutes at a height of $42 \mathrm{~cm}$ to kill the embryo ${ }^{[19]}$. These eggs were used for the preparation of Trichocards. One Cubic Centimetre (cc) eggs of Corcyra were sprinkled on each card smeared with a thin layer of diluted acacia gum with the help of a $5 \mathrm{ml}$ plastic vial having a perforated lid. After proper drying, the individual egg card was introduced in a plastic jar $(15 \mathrm{~cm} \times 25 \mathrm{~cm})$ having freshly emerged adults of $T$. japonicum. Adults of $T$. japonicum were fed with 5 per cent honey solution in the form of a fine streak on the inner wall of the bottle. Adults were allowed to parasitize Corcyra egg cards for 24 hours. The blackening of Corcyra eggs in the card indicated parasitization and these cards were kept as such for the emergence of adult parasitoids for further rearing during this investigation.

Table 1: Details of insecticidal treatment used against $T$. japonicum under laboratory condition

\begin{tabular}{|c|c|c|c|c|}
\hline Treat No. & Name of insecticide & Formulation & Concentration (\%) & Dose /1L of Water \\
\hline $\mathrm{T}_{1}$ & Flubendiamide & $39.35 \mathrm{SC}$ & 0.005 & $0.12 \mathrm{ml}$ \\
\hline $\mathrm{T}_{2}$ & Chlorantraniliprole & $18.5 \mathrm{SC}$ & 0.003 & $0.16 \mathrm{ml}$ \\
\hline $\mathrm{T}_{3}$ & Fipronil & $5 \mathrm{SC}$ & 0.007 & $1.4 \mathrm{ml}$ \\
\hline $\mathrm{T}_{4}$ & Thiacloprid & $21.7 \mathrm{SC}$ & 0.01 & $0.46 \mathrm{ml}$ \\
\hline $\mathrm{T}_{5}$ & Quinalphos & $25 \mathrm{EC}$ & 0.025 & $1.0 \mathrm{ml}$ \\
\hline $\mathrm{T}_{6}$ & Lambda- cyhalothrin & $5 \mathrm{EC}$ & 0.0005 & $0.1 \mathrm{ml}$ \\
\hline $\mathrm{T}_{7}$ & Thiamethoxam & $25 \mathrm{WG}$ & 0.003 & $0.12 \mathrm{~g}$ \\
\hline $\mathrm{T}_{8}$ & Control (Treated with water) & -- & -- & -- \\
\hline
\end{tabular}

\section{Contact toxicity of various insecticides against $T$. japonicum}

Contact toxicity of various insecticides (Table-1) was determined as per methodology suggested by Jalali and Singh [7] with slight modifications. A transparent plastic container $(6.5 \mathrm{~cm} \times 5 \mathrm{~cm})$ with a tight lid was converted into a pesticide - testing unit by cutting a small window on two sides and closing them with the fine muslin cloth, glued with waterproof glue to avoid the fumigant effect of insecticides and to provide aeration. The prepared solutions of various insecticides were sprayed on all inner sides of the respective container and lid with an atomizer and both were then airdried thoroughly under a ceiling fan for about 15-20 minutes. In the control treatment, only water spray was made during the present investigation. Thereafter, twenty newly emerged females were introduced inside each vial and exposed to the treated surface freely. Five per cent honey solution was also provided in the form of the fine streak as adult food. Observation on the adult mortality was recorded at 0 (after 2 hours), 12, 24, 48 and 72 hours after constant exposure. The moribund adults were considered as dead. Thus, the data obtained on per cent adult mortality were subjected to arcsine transformation and analyzed by using Split-Plot Completely Randomized Design for interpretation of results during the present investigation. For the laboratory screening of different insecticides to test their safety to adults, the response of toxicant exposure to Trichogramma adult female was categorized based on per cent adult mortality and further scores were assigned as follows (Anonymous, 1994) ${ }^{[2]}$.

\begin{tabular}{|c|c|c|c|}
\hline Sr. No. & Category & Adult mortality $\mathbf{( \% )}$ & Toxicity score \\
\hline 1 & Harmless & $<50$ & 1 \\
\hline 2 & Slightly harmful & 50 to 79 & 2 \\
\hline 3 & Moderately harmful & 80 to 99 & 3 \\
\hline 4 & Harmful & $>99$ & 4 \\
\hline
\end{tabular}

\section{Results and Discussion}

The contact toxicity of seven promising insecticides was tested against female $T$. japonicum at laboratory condition. The data in terms of per cent adult mortality recorded at $0 \mathrm{hrs}$ ( 2 hrs), 12, 24, 48 and 72 hours after insecticide treatment (HAT) are presented in Table-02 and depicted in Figure-01 and discussed as hereunder.

The data obtained at $0 \mathrm{hrs}(2 \mathrm{hrs})$ after treatment revealed that no adult mortality was recorded in control (water spray), flubendiamide $39.35 \mathrm{SC}$, chlorantraniliprole $18.5 \mathrm{SC}$ and lambda-cyhalothrin 5 EC. The perusal of the mortality data recorded at $12 \mathrm{hrs}$ after insecticide treatment indicated that control treatment $(0.00 \%)$ had nil adult mortality. Afterward, the treatment of flubendiamide39.35 SC recorded least adult mortality $(32.50 \%)$ and found safer for the parasitoid adult at $12 \mathrm{hrs}$ after treatment. Moreover, the treatment of insecticides viz., fipronil $5 \mathrm{SC}$, thiacloprid 21.7 SC and quinalphos $25 \mathrm{EC}$ caused cent per cent adult mortality and these were found harmful to female parasitic wasp at 12 hrs after treatment.

Table 2: Contact toxicity of different insecticides against adult female of $T$. japonicum under laboratory condition

\begin{tabular}{|c|c|c|c|c|c|c|c|c|c|}
\hline \multirow{2}{*}{\begin{tabular}{|c|} 
Treat. \\
No.
\end{tabular}} & \multirow{2}{*}{ Treatments } & \multirow{2}{*}{$\begin{array}{c}\text { Conc. } \\
(\%)\end{array}$} & \multicolumn{5}{|c|}{ Adult mortality (\%) at different intervals } & \multirow{2}{*}{$\begin{array}{c}\text { Treatment } \\
\text { mean }\end{array}$} & \multirow{2}{*}{$\begin{array}{c}\text { Toxicity } \\
\text { score }\end{array}$} \\
\hline & & & 0 (2 HAT) & 12 HAT & 24 HAT & 48 HAT & 72 HAT & & \\
\hline $\mathrm{T}_{1}$ & Flubendiamide $39.35 \mathrm{SC}$ & 0.005 & $6.42 *(0.00)$ & $34.74(32.50)$ & $59.20(73.75)$ & $83.58(100.00)$ & $83.58(100.00)$ & $53.50(61.25)$ & 2 \\
\hline $\mathrm{T}_{2}$ & Chlorantraniliprole $18.5 \mathrm{SC}$ & 0.003 & $6.42(0.00)$ & $69.39(87.50)$ & $83.58(100.00)$ & $83.58(100.00)$ & $83.58(100.00)$ & $65.31(77.50)$ & 2 \\
\hline $\mathrm{T}_{3}$ & Fipronil 5 SC & 0.007 & $83.58(100.00)$ & $83.58(100.00)$ & $83.58(100.00)$ & $83.58(100.00)$ & $83.58(100.00)$ & $83.58(100.00)$ & 4 \\
\hline
\end{tabular}




\begin{tabular}{|c|c|c|c|c|c|c|c|c|c|}
\hline $\mathrm{T}_{4}$ & Thiacloprid 21.7 SC & 0.01 & $50.04(58.75)$ & $83.58(100.00)$ & $83.58(100.00)$ & $83.58(100.00)$ & $83.58(100.00)$ & $76.87(91.75)$ & 3 \\
\hline $\mathrm{T}_{5}$ & Quinalphos 25 EC & 0.025 & $81.96(97.81)$ & $83.58(100.00)$ & $83.58(100.00)$ & $83.58(100.00)$ & $83.58(100.00)$ & $83.26(99.75)$ & 4 \\
\hline $\mathrm{T}_{6}$ & Lambda- cyhalothrin 5EC & 0.0005 & $6.42(0.00)$ & $48.60(56.25)$ & $83.58(100.00)$ & $83.58(100.00)$ & $83.58(100.00)$ & $61.15(71.25)$ & 2 \\
\hline $\mathrm{T}_{7}$ & Thiamethoxam $25 \mathrm{WG}$ & 0.003 & $27.34(21.25)$ & $64.61(81.25)$ & $83.58(100.00)$ & $83.58(100.00)$ & $83.58(100.00)$ & $68.54(80.50)$ & 3 \\
\hline $\mathrm{T}_{8}$ & Control (water) & -- & $6.42(0.00)$ & $6.42(0.00)$ & $6.42(0.00)$ & $29.85(25.00)$ & $38.44(38.75)$ & $17.51(12.75)$ & 1 \\
\hline \multicolumn{3}{|c|}{ Period mean } & $33.58(34.73)$ & $59.31(69.69)$ & $70.89(84.22)$ & $76.86(90.63)$ & $77.94(92.34)$ & & \\
\hline & & & \multicolumn{2}{|l|}{ S. Em \pm} & \multicolumn{2}{|c|}{ C.D. at 5\% } & \multicolumn{3}{|c|}{ C.V. $(\%)$} \\
\hline \multicolumn{2}{|r|}{ Treatment } & \multicolumn{3}{|c|}{0.40} & \multirow{2}{*}{\multicolumn{2}{|c|}{$\begin{array}{l}1.17 \\
0.81\end{array}$}} & \multicolumn{3}{|c|}{2.81} \\
\hline \multicolumn{2}{|r|}{ Period } & \multicolumn{3}{|c|}{0.29} & & & \multicolumn{3}{|c|}{2.53} \\
\hline & $\mathrm{T} \times \mathrm{P}$ & \multicolumn{2}{|r|}{0.81} & & \multicolumn{2}{|c|}{$\frac{0.81}{2.26}$} & \multicolumn{2}{|r|}{--} & \\
\hline
\end{tabular}

* Figures outside the parentheses are arc sine transformed values while those inside the parentheses are original values.

HAT $=$ Hours after Treatment

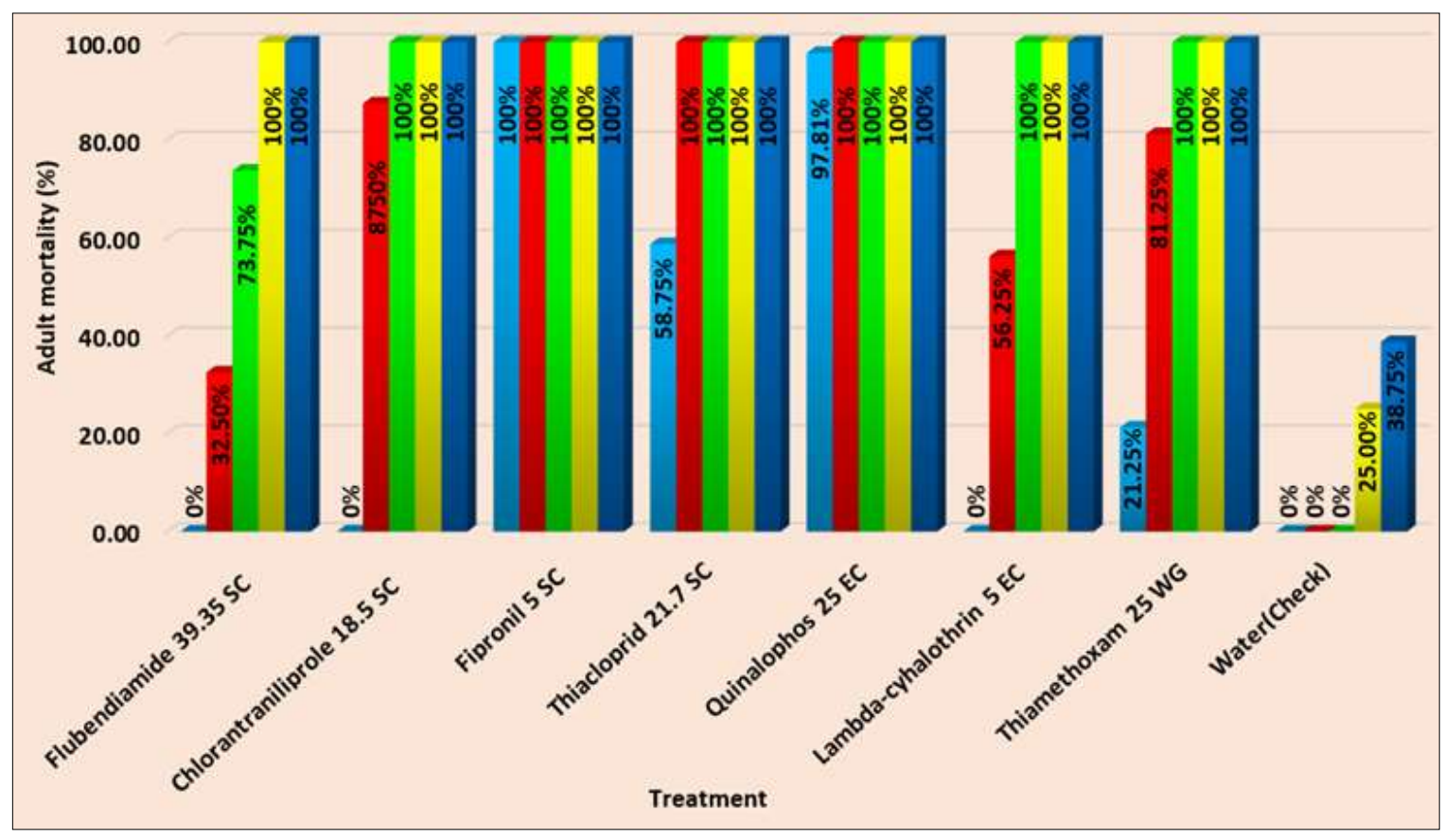

Fig 1: Contact toxicity of different insecticides against adult female of $T$. japonicum under laboratory condition

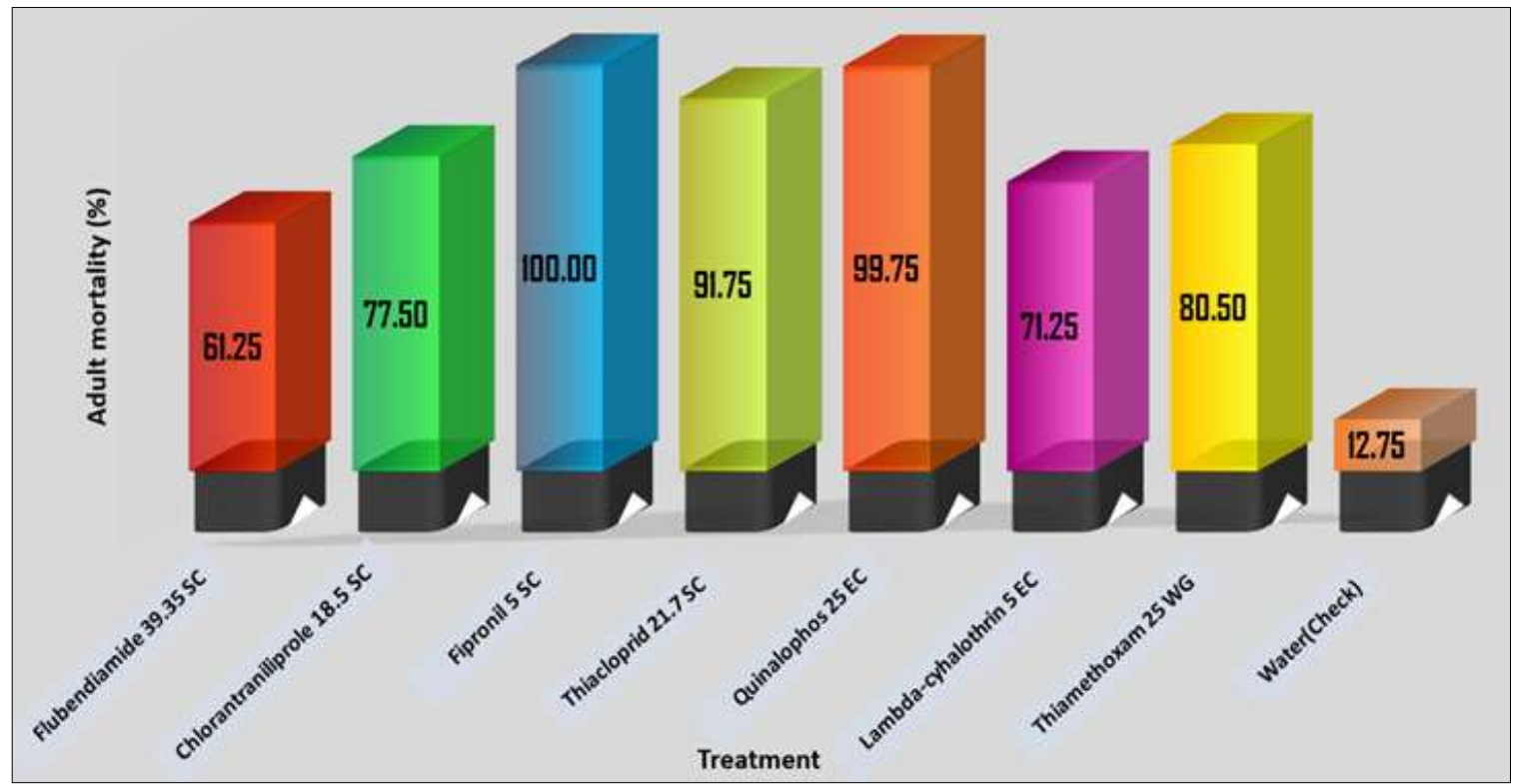

Fig 2: Contact toxicity of different insecticides against adult female of $T$. japonicum under laboratory condition (Based on treatment mean)

It can be seen from the data obtained at $24 \mathrm{hrs}$ after treatment that no adult mortality was observed with control treatment whereas the treatment of insecticides viz, chlorantraniliprole 18.5 SC, fipronil 5 SC, thiacloprid $21.7 \mathrm{SC}$, quinalphos 25 EC, lambda-cyhalothrin $5 \mathrm{EC}$ and thiamethoxam $25 \mathrm{WG}$ caused cent percent mortality of parasitoid adult and were considered as harmful to adults of T. japonicum at 24 hrs after treatment. The data on adult mortality at $48 \mathrm{hrs}$ after treatment indicated that exposure of all insecticides viz, flubendiamide39.35 SC, chlorantraniliprole 18.5 SC, fipronil $5 \mathrm{SC}$, thiacloprid $21.7 \mathrm{SC}$, quinalphos $25 \mathrm{EC}$, lambdacyhalothrin $5 \mathrm{EC}$ and thiamethoxam $25 \mathrm{WG}$ were found 
harmful to the female wasp showing cent per cent adult mortality at 48 hrs after treatment.

At 72 hrs after exposure, control treatment had 38.75 per cent adult mortality while all the tested insecticides were found detrimental to $T$. japonicum female and categorized under harmful to the female at $72 \mathrm{hrs}$ after treatment.

Looking to the overall mean data on the per cent adult mortality at 0 ( $2 \mathrm{hrs}), 12,24,48$ and $72 \mathrm{hrs}$ after treatment presented in Table-02 and depicted graphically in Figure-02, the results revealed that significantly lowest adult mortality of female of $T$. japonicum was recorded with control treatment $(12.75 \%)$. This was followed by flubendiamide39.35 SC (61.25\%) and lambda-cyhalothrin 5 EC (71.25\%). Further, fipronil 5 SC showed cent per cent adult mortality of parasitic wasp and it was considered as deadly harmful to the adult of $T$. japonicum. Moreover, the toxicity of remaining insecticides was intermediate in action viz., quinalphos $25 \mathrm{EC}$ (99.75\%), thiacloprid $21.7 \mathrm{SC}(91.75 \%)$, chlorantraniliprole 18.5SC (77.50\%) and thiamethoxam 25 WG (80.50\%).Thus, based on the above results, it can be concluded that the contact toxicity of different treatments to the $T$. japonicum adults in ascending order were control (water) < flubendiamide39.35 SC < lambda-cyhalothrin 5 EC < chlorantraniliprole $18.5 \% \mathrm{SC}<$ thiamethoxam $25 \mathrm{WG}<$ thiacloprid $21.7 \mathrm{SC}<$ quinalphos $25 \mathrm{EC}<$ fipronil $5 \mathrm{SC}$. Based on the above results, the ranking of the various insecticides was made and presented hereunder.

\begin{tabular}{|c|c|c|}
\hline Toxicity score & Category & Perceived insecticides \\
\hline 1 & $\begin{array}{c}\text { Harmless } \\
(<50 \% \text { mortality })\end{array}$ & Nil \\
\hline 2 & $\begin{array}{c}\text { Slightly harmful } \\
(50 \text { to 79\% mortality) }\end{array}$ & $\begin{array}{c}\text { Flubendiamide39.35 SC } \\
\text { Chlorantraniliprole 18.5 SC } \\
\text { Lambda-cyhalothrin 5 EC }\end{array}$ \\
\hline 3 & $\begin{array}{c}\text { Moderately harmful } \\
\text { (80 to 99\% mortality) }\end{array}$ & $\begin{array}{c}\text { Thiacloprid 21.7 SC } \\
\text { Thiamethoxam 25 WG }\end{array}$ \\
\hline 4 & $\begin{array}{c}\text { Harmful } \\
(>99 \% \text { mortality })\end{array}$ & $\begin{array}{c}\text { Fipronil 5 SC } \\
\text { Quinalphos 25 EC }\end{array}$ \\
\hline
\end{tabular}

From all the above results, it is ascertained that none of the insecticide was found safer except control treatment to the adults of $T$. japonicum under contact toxicity trial during the present investigation. However, insecticides viz., Flubendiamide 39.35 SC, chlorantraniliprole 18.5 SC and lambda-cyhalothrin 5 EC were considered as slightly harmful. Furthermore, thiamethoxam $25 \mathrm{WG}$ and thiacloprid $21.7 \mathrm{SC}$ were found moderately harmful to the adults of T. japonicum. Moreover, fipronil $5 \mathrm{SC}$ and quinalphos $25 \mathrm{EC}$ were found detrimental and grouped as harmful to adults of $T$. japonicum (Figure-03). The present investigation demonstrated that a high degree of variation with respect to effect was found among the tested insecticides and various insecticides possessed significantly different risks to the adults of T. japonicum, which could provide the useful information for integration of biological control with chemical control. The present findings are corroborated with the results reported by Sun et al. (2008) [21] who noticed that fipronil and thiamethoxam had detrimental effect on survival of adult $T$. japonicum and found harmful to adult wasp. Later on, Pawar et al. (2020) [16] classified thiamethoxam as moderately harmful to adults of $T$. japonicum whereas Khan (2019) [9] showed that fipronil caused cent per cent mortality of $T$. chilonis within $24 \mathrm{hrs}$ of exposure to 1-day old pesticide residue and categorized as harmful insecticide. Furthermore, Preetha et al. (2009) ${ }^{[17]}$ and Ko et al. (2015) ${ }^{[11]}$ reported that thiamethoxam was most toxic to adults of $T$. chilonis among all the investigated insecticides. Cheng et al. (2018) [4] reported that thiamethoxam was found moderately harmful to adults of $T$. dendrolimi and T. ostriniae and slightly toxic to the adultsof $T$. chilonis. The result further noted that cyhalothrin was considered as slightly harmful to adult wasp of $T$. dendrolimi and $T$. ostriniae while it was found moderately harmful to the adults of $T$. chilonis which is more or less in accordance with the present findings. In contrast to above scientists, Uma et al. (2014) [22] categorized thiamethoxam and fipronil as slightly harmful to $T$. japonicum

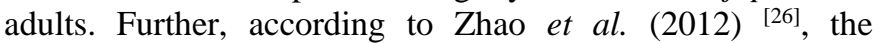
fipronil, thiacloprid and lambda-cyhalothtrin was found harmless to the adults of $T$. japonicum whereas thiamethoxam was considered as slightly harmful to adult wasp during the investigation which again differs with the present investigation. Jiang et al. (2019) ${ }^{[8]}$ reported that thiacloprid and thiamethoxam were found slightly harmful to the adults of all three tested trichogramma parasitoid viz., T. dendrolimi, $T$. ostriniae and T. confusum which disagrees with the present investigation.

Lateron, Pawar et al. (2020) ${ }^{[16]}$ who discovered that lambdacyhalothrin caused cent per cent mortality of adult T.Japonicum and classified as harmful to adult wasp while thiacloprid was categorized as slightly harmful to adults of $T$. japonicum. The findings of present investigation disagree with Abdulhay and Rathi (2014) [1] who demonstrated that thiacloprid listed as slightly harmful to the adult of $T$. evanescens and Carvalho et al. (2006) ${ }^{[3]}$ who reported that thiamethoxam, thiacloprid and lambda-cyhalothrin were categorized as harmless, slightly harmful and moderately harmful to the adult of $T$. pretiosum, respectively. The present investigation showed that flubendiamide and chlorantraniliprole were slightly harmful to the $T$. japonicum adults which is in line of the findings of past workers viz., Uma et al. (2014) ${ }^{[22]}$ and Pawar et al. (2020) ${ }^{[16]}$ who found that flubendiamide was categorized as slightly harmful to adults of T. japonicum and Hussain et al. (2012) ${ }^{[6]}$ who revealed that flubendiamide and chlorantraniliprole showed toxic effect on the adults of $T$. chilonis after $24 \mathrm{hrs}$ of exposure with 14 and 8 per cent adult survival, respectively. Moreover, Sattar et al. (2011) ${ }^{[18]}$ recorded that flubendiamide was categorized as harmless with 28 per cent mortality of $T$. chilonis adult after 24 hours of exposure. A number of workers such as, Khan (2019) ${ }^{[9]}$ and Preetha et al. (2009) ${ }^{[17]}$ listed chlorantraniliprole was harmless to T. chilonis while, Uma et al. (2014) ${ }^{[22]}$ and Pawar et al. (2020) ${ }^{[16]}$ recorded chlorantraniliprole was harmless to adult $T$. japonicum. The findings of Singh and Varma (1986) ${ }^{[20]}$ also support the present investigation that quinalphos caused cent per cent mortality of adults of $T$. brasiliensis at $24 \mathrm{hrs}$ after treatment. In contrast to this, Uma et al. (2014) ${ }^{[22]}$ reported that quinalphos was slightly harmful to adults of $T$. japonicum. Furthermore, findings of some workers disagree with the present findings. This discrepancy in contact toxicity of various insecticides against female of $T$. japonicum might be due to doses of insecticides used, tested insecticides and methodology adopted for their investigation. 


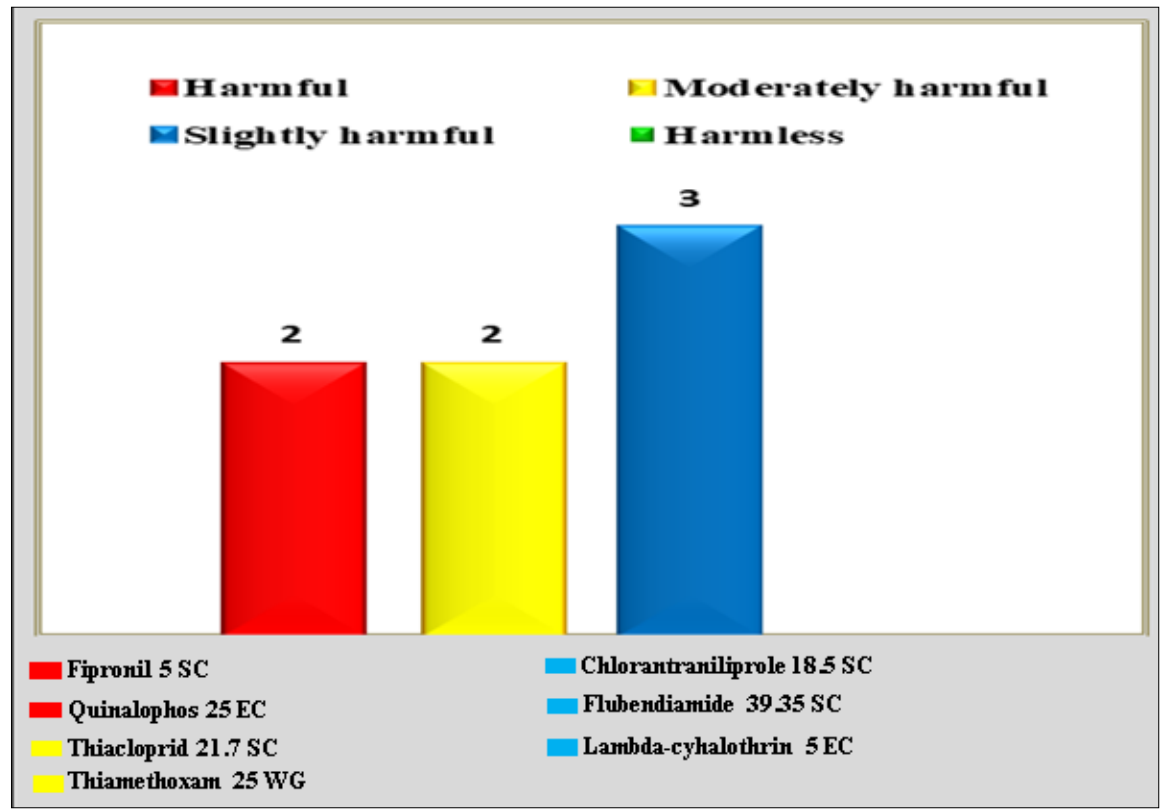

Fig 3: Classification of different insecticides based on their contact toxicity against adult female of $\mathrm{T}$. japonicum under laboratory condition

\section{Conclusion}

The present investigation indicated that there was no insecticide under testing found totally safer to the $T$. japonicum. Hence, the use of moderately harmful and harmful insecticides should be avoided upto $72 \mathrm{hrs}$ after release of parasitoid as well as during the peak activity period of parasitoid under field condition. Moreover, keeping the view of possible detrimental effect of the tested insecticides, the integration of these insecticides should be considered with utmost care during the implementation of IPM programme in agro-ecosystem.

\section{Acknowledgement}

Investigators are thankful to Director of Research and Dean P.G. Studies, NAU, Navsari (Gujarat) for providing the necessary facilities to carry out the present investigation. Author is also grateful to Professor and Head \& In-charge, Biological Control Laboratory, Department of Entomology, N. M. College of Agriculture, Navsari Agricultural University, Navsari for providing the laboratory facilities throughout the research work.

\section{References}

1. Abdulhay HS, Rathi MZ. Effect of some insecticide on egg parasitoid, Trichogramma evanescens Westwood (Hymenoptera: Trichogrammatiodae). Journal of AlNahrain University 2014;17(3):116-123.

2. Anonymous. Trichogrammatids Project Directorate of Biological Control, Bangalore, Technical Bulletin 1994;7:1-93.

3. Carvalho GA, Moura AP, Bueno VHP. Side effects of pesticides on Trichogramma pretiosum (Hymenoptera: Trichogrammatidae). Integrated Control in Protected Crops, Mediterranean Climate IOBC/wprs Bulletin 2006;29(4):355-359.

4. Cheng S, Lin R, Wang L, Qiu Q, Qu M, Ren X et al. Comparative susceptibility of thirteen selected pesticides to three different insect egg parasitoid Trichogramma species. Ecotoxicology and Environmental Safety 2018;166:86-91.

5. Desneux N, Decourtye A, Delpuech JM. The sublethal effects of pesticides on beneficial arthropods. Annual Re view of Entomology 2007;52:81-106.

6. Hussain D, Ali A, Muhammad M, Ali S, Muhammad S, Nadeem S. Evaluation of toxicity of some new insecticides against egg parasitoid Trichogramma chilonis (Ishii) (Hymenoptera: Trichogrammitidae). Pakistan Journal Zoology 2012;44(4):1123-1127.

7. Jalali SK, Singh SP. Susceptibility of various stages of Trichogrammatoidea armigera Nagaraja to some pesticides on survival and parasitising ability. Biocontrol Science and Technology 1993;3:21-27.

8. Jiang J, Liu X, Huang X, Yu X, Zhang W, Zhang X et al. Comparative ecotoxicity of neonicotinoid insecticides to three species of Trichogramma parasitoid wasps (Hymenoptera: Trichogrammatidae). Ecotoxicology and Environmental Safety 2019;183:1-7.

9. Khan MA. Lethal and parasitism effects of selected novel pesticides on adult Trichogramma chilonis (Hymenoptera: Trichogrammatidae). Journal of Plant Diseases and Protection 2019;127:81-90 (DOI: https://doi.org/10.1007 /s41348-019-00280-2).

10. Ko K, Liu Y, Hou M, Babendreier D, Zhang F, Song K. Evaluation for potential Trichogramma (Hymenoptera: Trichogrammatidae) strains for control of the striped stem borer (Lepidoptera: Crambidae) in the Greater Mekong Subregion. Journal of Economic Entomology 2014;107:955-963.

11. Ko K, Liu Y, Hou M, Babendreier D, Zhang F, Song K. Toxicity of insecticides targeting rice plant hoppers to adult and immature stages of Trichogramma chilonis (Hymenoptera: Trichogrammatidae). Journal of Economic Entomology 2015;108(1):69-76 (DOI: http://dx.doi.org/ 10.1093/ jee/tou053).

12. Kumar GA, Jalali SK, Venkatesan T, Nagesh M, Lalitha Y. Genetic improvement of Trichogramma chilonis Ishii for combined tolerance to multiple insecticides and high temperature. Journal of Biological Control 2008;22(2):347-356.

13. Lou YG, Zhang GR, Zhang WQ, Hu Y, Zhang J. Reprint of: Biological control of rice insect pests in China. Biological Control 2014;68:103-116.

14. Naganna R, Shinde CU. Biology of Ecto-larval parasitoid, Goniozus nephantidis (Muesebeck) 
(Bethylidae: Hymenoptera) on Rice moth, Corcyra cephalonica (Stainton). Trends in Biosciences 2017;10(24):4986-4993.

15. Naganna R, Shinde CU. Parasitic potential of Ecto-larval parasitoid, Goniozus nephantidis (Muesebeck) (Bethylidae: Hymenoptera) on Corcyra cephalonica (Stainton). Trends in Biosciences 2017;10(24):49264929.

16. Pawar RD, Sawai HR, Thakare VS, Wankhade SV. Evaluation of safety of some new insecticides to per cent parasitisation and survival of Trichogramma japonicum. Journal of Entomology and Zoology Studies 2020;8(3):685-689.

17. Preetha G, Stanley J, Suresh S, Kuttalam S, Samiyappan R. Toxicity of selected insecticides to Trichogramma chilonis: Assessing their safety in the rice ecosystem. Phytoparasitica 2009;37:209-215 (DOI: https://dx.doi.org/ 10.1007/s12600-009-0031-x).

18. Sattar S, Farmanullah Saljoqi AR, Muhammad A, Sattar H, Qazi JI. Toxicity of some new insecticides against Trichogramma chilonis (Hymenoptera: Trichogrammatidae) under laboratory and extended laboratory conditions. Pakistan Journal Zoology 2011;43(6):1117-1125.

19. Shinde CU, Radadia GG, Ghetiya LV, Shah KD, Gadhiya VC, Patel AD. Effect of non-ionizing (UV) radiation on the development of egg parasitoid, Trichogramma chilonis Ishii (Hymenoptera: Trichogrammatidae). Advances in Life Sciences 2016;5(22):10357-10361.

20. Singh PP, Varma GC. Comparative toxicities of some insecticides to Chrysoperla carnea (Chrysopidae: Neuroptera) and Trihogramma brasiliensis (Trichogrammatidae: Hymenoptera), two arthropod natural enemies of cotton pests. Agriculture, Ecosystems and Environment 1986;15:23-30.

21. Sun CS, Jian YS, Jin L, Zang Xi. Laboratory safety evaluation of insecticides to Trichogramma japonicum. Chienes Journal of Rice Science 2008;22(1):93-98 (URL: https://www.google.com/amp/s/www.researchgate.net/pu blication/285483690_Laboratoy_safety_evaluation_of_in secticides_to_Trichogramma_japonicum/amp.).

22. Uma S, Jacob S, Lyla KR. Acute contact toxicity of selected conventional and novel insecticide to Trichogramma japonicum Ashmead (Hymenoptera: Trichogrammatidae). Journal of Biopesticide 2014;7(Supp.):133-136.

23. Wahengbam J, Raut AM, Mandal SK, Banu AN. Efficacy of new generation insecticides against Trichogramma chilonis Ishii and Trichogramma pretiosum Riley. Journal of Entomology and Zoology Studies 2018;6(1):1361-1365.

24. White B. Biological control of insect pests. ETP Publication, Waltham Abbey Essex, USA 2019, 76(URL: https://books.google.co.in/books?id=jOTEDwAAQBAJ \&lpg=PA76\&ots=GWGeYLzbS0\&dq=how $\% 20 \mathrm{much} \% 2$ 0hectare $\% 20$ of $\% 20$ area\%20is\%20treated $\% 20$ with $\% 20$ tri chogramma $\% 20$ annualy $\% 20$ across $\% 20$ world \&pg=PP6\#v $=$ onepage $\& \mathrm{q}=$ how $\% 20$ much $\% 20$ hectare $\% 20$ of $\% 20$ area $\% 20$ is\%20treated\%20with\%20trichogramma\%20annualy $\% 20$ across \%20world\&f=false).

25. Yousuf M, Ikram M, Faisal M. Current status of Indian Trichogramma spp. along with their distributional record and host range. Indian Forester 2015;141(7):806-812.
26. Zhao X, Wu C, Wang Y, Cang T, Chen L, Yu R et al. Assessment of toxicity risk of insecticides used in rice ecosystem on Trichogramma japonicum, an egg parasitoid of rice lepidopterans. Journal of Economic Entomology 2012;105(1):92-101 (DOI: http://dx.doi.org/ 10.1603/ EC11259). 